\title{
Assistive Technology and Older Adults in Disasters: Implications for Emergency Management
}

\author{
Mary Helen McSweeney-Feld, PhD
}

\section{ABSTRACT}

This article identifies concepts, trends, and policy gaps in the availability and service delivery of assistive technology utilized by older adults in disasters, as well as implications for emergency management planning and shelter administration. Definitions of types of assistive technology, as well as views of older adults using technology as at-risk individuals for emergency management service provision, are provided. An overview of peer-reviewed articles and gray literature is conducted, focusing on publications from 2001 to the present in the United States. Analytical frameworks used by emergency management organizations as well as regulations such as the Americans with Disabilities Act and recent court decisions on emergency shelter accessibility in disasters are reviewed. Research on the use of assistive technology by older adults during disasters is a neglected issue. The current and potential benefits of defining standards for provision and use of assistive technology for older adults during disasters has received limited recognition in emergency management planning. Older adults with disabilities utilize assistive technology to maintain their independence and dignity, and communities as well as emergency services managers need to become more aware of the needs and preferences of these older adults in their planning processes and drills as well as in service delivery during actual events. (Disaster Med Public Health Preparedness. 2017;11:135-139)

Key Words: assistive technology, disasters, older adults, individuals with access and functional needs, emergency management

$\mathrm{T}$ he number of adults over age 65 in the United States is estimated to reach 84 million, or over $20 \%$ of the US population, by $2050 .^{1}$ Rapid growth in the number of older adults in the United States, primarily due to the baby boomer population, is also seen in global population estimates of adults over age 60 , the number of which is estimated to be 2.1 billion by $2050 .^{2}$ As people grow older and the probability of having disabilities and limitations in activities of daily living grows, use of assistive technology, that is, alternate and augmentative communication equipment, devices, strategies, tools, and supportive services that allow individuals to live in their homes with dignity and autonomy, may increase. ${ }^{3}$ Using a conservative estimate of $20 \%$ of the population age 60 and over being in need of assistive devices leads to a global estimate of at least 800 million items being used by older adults by $2050 .{ }^{4}$ To meet the needs of this population, assistive devices and technology need to be available and accessible for this population, affordable and appropriate for their needs, and safe for their use. ${ }^{4}$ This need becomes even more important when disasters occur, as these devices may be lost or damaged or unavailable owing to associated services needed for their operation such as electrical power and refrigeration. Evacuations also complicate the use of assistive technology.
The Federal Emergency Management Agency (FEMA) estimates that more than $50 \%$ of individuals visiting a disaster recovery center have a disability or an access or functional need that limits their ability to take actions. ${ }^{5}$ Alternate staging areas and emergency shelters may not be equipped with a wide array of devices and supportive services that allow older adults with disabilities or access and functional needs to be supported during these events.

The aim of this article was to provide an overview of assistive, alternate, and augmentative communication technologies utilized by older adults living in the community as well as in residential care communities and the issues involved when these individuals are impacted by an emergency or a disaster. Definitions of terms, as well as a review of prevailing regulations and research on this topic are provided, as well as policy and research gaps concerning this population. Recommendations for future data collection and research, as well as consistent policies, conclude the article.

\section{METHODS}

A review of terminology pertaining to the older adult population, as well as definitions of various types of assistive technology, is provided. Given the large range 
of literature that could pertain to this topic, a search was conducted by using key words pertaining to the older adult population with disabilities and access or functional limitations (key words: "ageing," "aging," "elderly," "seniors," “disabilities," "function") combined with key words relating to assistive technology (key words: "assistive device," "assistive technology," "medical device"), and key words relating to emergency management (key words: "disasters," "emergencies," "emergency management"). Examples of how the older adult population uses assistive technology outside the United States were excluded owing to differences in emergency management policy and regulations. Gray literature was sourced through government emergency management and health care websites pertaining to emergency management, as well as individuals with disabilities and functional needs. Material was included if it addressed issues of older adults and assistive technology use in emergencies or disasters and met criteria such as a report or peer-reviewed proceedings from a conference, training programs published by federal government agencies or recognized consultants in the field of disabilities management, surveys of older adults and assistive technology use, presentations by government or consulting organizations that contract with governmental agencies, or reports on assistive technology and its use in emergencies or disasters.

\section{RESULTS}

The themes emerging from this review could be organized into 4 sections: (1) definitions of assistive technology categories and a framework for service provision for older adults who use assistive technology affected by a disaster, (2) issues affecting older adults using assistive technology in a disaster who are living in communities vs residential facilities, (3) issues that arise when disasters occur and affect older adults using assistive technology, and (4) issues affecting evacuations of older adults using assistive technology in a disaster.

\section{Older Adults Using Assistive Technology: An Overview}

In order to fully understand the needs of older adults using assistive technology in disasters, some definitions need to be provided to fully encompass the diversity of this population. For purposes of emergency management, older adults utilizing assistive technology should be treated as individuals with disabilities as defined under the Americans with Disabilities Act (ADA), that is, as individuals with a physical or mental impairment that substantially limits one or more of their life activities, a record of such an impairment, or being regarded as having an impairment ${ }^{6}$ instead of characterizing their needs because of their chronological age. ${ }^{7}$ This population may also have multiple chronic conditions and physical disabilities necessitating their use of assistive technology. ${ }^{8}$ The 2008 Amendments to the ADA also expanded the definition of major life activities and included major bodily functions. The major life activities include caring for oneself, performing manual tasks, seeing, hearing, eating, sleeping, walking, standing, lifting, bending, speaking, breathing, learning, reading, concentrating, thinking, communicating, and working. Major bodily functions include, but are not limited to, functions of the immune system, normal cell growth, and digestive, bowel, bladder, neurological, brain, respiratory, circulatory, endocrine, and reproductive functions. ${ }^{9}$ Assistive technology may be used to maintain any or all of these expanded life activity functions, and being able to use technology in a disaster becomes a critical component of accommodation of an older adult's needs.

Older adults using assistive technology may have functional limitations which, due to physical or mental impairment, require the individual to use special services or accommodations not typically made for other individuals. These limitations may include mobility limitations, sensory limitations, or intermittent chronic conditions that require them to use assistive devices such as a cane, walker, or wheelchair for ambulation, balance, or general mobility; vision or hearing aids; or a personal emergency response system that alerts a 24-hour call center in a health emergency. Still others may have aged in the community or in a residential care facility with developmental or intellectual disabilities requiring use of special devices and equipment.

In addition to functional limitations, older adults using assistive technology may have access needs in a disaster such as the ability to obtain medical care, remaining independent, supervision, or utilizing transportation services. Other individuals within this group may have communication deficits caused by aphasia (impairments in speech or language modalities) or apraxia (a motor speech disorder where the individual cannot express their wishes correctly) that occurs at birth or due to a chronic condition such as brain injury or stroke or dementia that limits their ability to communicate with others. Consequently, if they utilize assistive technology, an older adult can best be described as an individual with access and functional needs that impact their ability to respond to an emergency or disaster, as well as the resources that they would need in such an event.

The ADA also requires that individuals with disabilities have the right to be accommodated in the most integrated setting appropriate for their needs, otherwise known as the integration mandate. ${ }^{10}$ To comply with this mandate, many communities have established emergency preparedness committees with multidisciplinary membership that can collaborate and address the needs of older individuals with access and functional needs. While specialized services and medical shelters may be created in some areas for individuals utilizing assistive technology, it is important to note that there should not be a mandate for individuals to use these services if they believe that they can be accommodated in community shelters. The recent experience in 2016 of South Carolina's disaster response for individuals with disabilities showed the importance of this option for older adults. ${ }^{11}$

Assistive technology can include any item, piece of equipment, whether acquired or off the shelf, modified or customized, that is 
used to increase, maintain, or improve functional capacities of individuals with disabilities. ${ }^{12}$ Augmentative and alternate communication includes all forms of communication other than oral speech that are used to express thoughts, needs, wants, and ideas. ${ }^{13}$ Older adults with communication issues may rely on specialized equipment such as electronic speech-generating devices, picture and symbol communication boards, iPads with special communication applications, or specialized language such as American Sign Language to convey their ideas and wishes. ${ }^{14}$

Assistive technology and augmentative and alternate communication helps older adults maintain their ability to communicate, functional capacity, and mobility and provides a safe and supportive environment. However, elders using these assists may become isolated, or may experience stigma as the result of needing specialized assistance. ${ }^{15}$ Needed technology may also not be used or kept in working order by elders owing to the expense of the device or its replacement or repair cost. The complexity of the needs of this diverse group of elders presents many challenges in meeting their needs during emergency planning or the onset of an actual disaster.

\section{Older Adults and Assistive Technology Use in a Disaster}

When a disaster occurs, assistive technology may not function properly, or it may be lost or damaged. Loss of power can affect any assistive devices that need electricity, and backup batteries may not always be at hand. If medications are characterized as types of assistive supports, loss of medication access or pharmacy refills, or loss of refrigeration needed for some types of medications, may also not be present if a disaster has occurred. ${ }^{16}$ Even more critical are notification systems for individuals with sensory limitations or communication issues, and notification systems that utilize captioned messages may not be available in all geographical areas.

FEMA takes a whole community approach to emergency management, which in the case of older adults with disabilities and functional needs means that these adults are included in mitigation efforts and their needs are served by the resources available in the entire community. ${ }^{5}$ In the case of individuals with specialized needs, a 5-part methodology called the C-MIST framework was developed by June Kailes to identify the access and functional needs of individuals with disabilities before, during, and after a disaster. ${ }^{17}$ FEMA uses this framework in its emergency management training pertaining to individuals with access and functional needs. C-MIST stands for communication; maintaining health; independence; safety, support, and selfdetermination; and lastly, transportation. In this approach, assistive technology and communication devices and supports are typically enough to maintain older adults' support and independence in the event of an emergency or disaster. However, if individuals lose the support of these devices or services, they may need additional assistance to maintain their safety and right to self-determination in the amount, kind, and duration of the assistance that they require. ${ }^{17}$ If the event requires older adults utilizing assistive technology to evacuate, the provision of accessible transportation as well as communication about the availability of this transportation in alternate formats is essential to support the needs of this group of at-risk elders.

The needs of older adults using assistive technology who live in the community may also be difficult to identify. Traditional methods of identifying adults with access and functional needs have relied on their self-identification through a specialized registry for adults needing these services. However, disability advocates have recommended that emergency management services move away from the use of these lists because they can easily become outdated if individuals move, have changing needs, or die and may not appeal to individuals with access and functional limitations for fear of stigmatization as a result of their conditions. ${ }^{18}$ Geographic information system mapping has also been identified as another key technology that can assist communities in locating frail elders with technology needs, ${ }^{19}$ as well as community response grids rooted in an offline physical community supplemented with information and communication technology and exchanges. ${ }^{20}$ Social media communities such as Facebook and LinkedIn have also helped to provide notifications of disasters to individuals with communication needs in accessible formats. Another neglected area of study is the use of service animals by older adults with disabilities as a form of supportive service that assists an individual in maintaining their dignity and autonomy in a disaster.

Individuals living in residential long-term care communities that utilize assistive technology may have a different set of needs in the event of a disaster. The Centers for Medicare and Medicaid Services (CMS) recommends that facilities participating in the federal Medicare program utilize a recommended Emergency Preparedness Tool for Healthcare Facilities (the Checklist) which provides detailed guidance on how to plan for disasters requiring shelter-in-place as well as evacuation needs. ${ }^{21}$ The Checklist provides detailed guidance to administrators on how to prepare for the needs of older adults using assistive technologies using FEMA's all-hazards, community-based approach to emergency management. The Checklist also emphasizes the importance of having generators to supply power for needed equipment and refrigeration, modified equipment for residents if their devices are not available or functioning, trained caregivers who are available to provide services, and notification of concerned family members who are entitled to know the location of their loved ones. However, residential communities that do not participate in the federal Medicare program are not necessarily covered under the provisions of the CMS emergency preparedness Checklist. In these cases, it is typically up to states or industry associations for these residences to recommend inclusive emergency preparedness measures, including instructions on how to respond to various types of events. 


\section{Older Adults and Assistive Technology: Evacuation Considerations}

When evacuations occur, populations of older adults using assistive technology encounter new concerns. Identification of individuals needing assistance, as well as access to their residences can post a multitude of challenges. ${ }^{22}$ These include ADA requirements for individuals with disabilities to be accommodated in the most integrated setting appropriate to their needs, ${ }^{10}$ as well as the ADA Design Requirements for Accessible Egress. $^{23}$ In addition, Section 508 of the Rehabilitation Act of 1973 requires that any accommodations provided are fully accessible. These provisions mandate that older adults with disabilities have the right to be accommodated in mass shelters that meet ADA requirements for accessibility, including the provision of accessible entrances and exits, assistive technology, sleeping and toileting provisions that are appropriate, and supportive services such as American Sign Language interpreters if needed for individuals with hearing limitations. ${ }^{24}$ If individuals utilize caregivers or service animals, these supportive assists also need to be accommodated in the shelter settings. ${ }^{25}$ The FEMA Office of Disability Integration Coordination also utilizes Seven Principles of Access for individuals with access and functional needs. These principles are as follows: equal access of this population to programs and services, physical access to locations of emergency programs and services, access to effective communication and information, inclusion of all individuals in emergency management programs and services, integrated settings for emergency programs, availability of modifications to meet the needs of individuals requiring special services, and no cost for access and use of these services. $^{5}$

Recent lawsuits regarding the inclusion of individuals with disabilities in disaster planning have also changed the nature of emergency management services. Two key court cases-the Communities Actively Living Independently $\mathbb{B}$ Free v. City of Los Angeles case in $2011^{26}$ and Brooklyn Center for Independence of Disabled v. Bloomberg in $2013^{27}$ - underscore the need for localities to provide notification systems for individuals with cognitive and sensory impairments in the event of an emergency or disaster, as well as evacuation plans, shelter accessibility, and communication appropriate for their needs. ${ }^{28}$ In another recent case focusing on communication issues, the City of New York was enjoined from removing street alarm boxes that provided deaf individuals with an effective, accessible means of directly reporting emergencies to 911 from the street. ${ }^{29}$ The recent experience of individuals with disabilities that were evacuated in the 2016 South Carolina floods showed the challenges of disaster services management in a community that had established emergency preparedness coalitions for individuals with access and functional needs, but still had difficulty obtaining American Sign Language interpreters, therapists, and cots for individuals with functional limitations for local shelters. ${ }^{11}$ Combined with the ADA, Section 508, CMS and FEMA requirements, shelter accessibility, location, resources that can supplement or replace lost or damaged devices, provisions for specialized therapists, caregivers and service animals, as well as trained shelter staff have become key components of planning for older adults using assistive technologies.

\section{DISCUSSION}

Numerous research and policy gaps exist in the area of older adults who utilize assistive technology in emergencies or disasters. Research on the needs of older adults in disasters is limited to a small number of resources, ${ }^{30,31}$ and the effects of these events on this population are known in only limited ways. ${ }^{32}$ While federal regulations, CMS and FEMA guidelines, and recent court cases have brought issues of planning and providing emergency management services to older adults, these initiatives are relatively recent in nature. Little to no studies exist of how these guidelines were effectively implemented, nor are regulations and guidelines for health care facilities not covered under CMS uniform or clear from state to state. With the passage of the Affordable Care Act in 2010, more policy and reimbursement incentives exist to keep older adults with disabilities in their homes in the community, and as this population grows, so too will their need for assistive devices and supports. ${ }^{33}$ Moreover, new types of assistive technology such as smart homes that use technology to support older adults needing assistance, as well as more digital and Internet-based technologies will continue to grow. ${ }^{34}$ However, the ability of these supports to function seamlessly in a disaster, as well as their ability to thwart any types of cybersecurity attacks or interruptions, has not been studied. Research on coordinated processes and planning exist in a handful of states such as Florida, California, Louisiana, and South Carolina, but in many areas, all-hazards, community-based disaster drills frequently exclude long-term care residential communities such as nursing homes or groups of older adults using assistive devices in the community. ${ }^{35}$ The Emergency Services Framework, Section 8 (ESF-8), health care coalitions that are part of the US Department of Health and Human Services Hospital Preparedness Programs have public health and hospital system representatives but do not have a clear mandate to include representatives from long-term care communities or advocates for individuals with disabilities living in the community in these coalitions. ${ }^{36}$

\section{CONCLUSIONS AND RECOMMENDATIONS}

A comprehensive approach to emergency management services for older adults using assistive technology starts with clear definitions of the needs and capabilities of this population and the technology that they require. Research on older adults using assistive technology is limited, and more targeted programs for this population in emergencies and disasters need to be developed.

However, in order for this to occur, capacity-building within communities must take place so that a true all-hazards, community-based approach to emergency preparedness for groups of at-risk individuals using assistive devices is possible. In addition, studies of the extent to which new assistive technologies can perform in the event of a disaster or a major 
cybersecurity event have yet to be developed. A communications strategy should also be developed and mandated so that all individuals with communications limitations are provided with accessible, captioned notification of emergency drills, actual emergency events, and the need to evacuate to shelters. A uniform strategy for ensuring that all shelters, including those in state and local areas, comply with ADA and other accessibility requirements also needs to be developed so the needs of older adults using assistive technology in a disaster can be supported.

\section{About the Author}

Department of Interprofessional Health Studies, Towson University, Towson, Maryland.

Correspondence and reprint requests to Mary Helen McSweeney-Feld, PhD, Department of Interprofessional Health Studies, Linthicum Hall 121D, Towson University, 8000 York Road, Towson, MD (e-mail: mmcsweeneyfeld@towson.edu).

\section{Acknowledgments}

I would like to acknowledge the National Center for Disaster Medicine and Public Health and their Caring For Older Adults in a Disaster online curriculum that served as the foundation for this article.

Published online: November 21, 2016.

\section{REFERENCES}

1. He W, Larsen LJ. Older Americans with a Disability: 2008-2012. American Community Survey Reports ACS-29. Washington, DC: US Government Printing Office; 2014.

2. United Nations. World Population Prospects The 2015 Revision: Key Findings and Advance Tables. New York, NY: Department of Economic and Social Affairs, Population Division, United Nations; 2015.

3. Ivanoff SD, Sonn U. Changes in the use of assistive devices among 90-year old persons. Aging Clin Exp Res. 2005;17:246-251. doi: 10.1007/ BF03324604

4. Garcon L, Khasnabis C, Walker L, et al. Medical and assistive health technology: meeting the needs of aging populations. Gerontologist. 2016;56(S2):S293-302. doi: 10.1093/geront/gnw005

5. Federal Emergency Management Association. IS-368: Including People with Disabilities and Others with Access and Functional Needs in Disaster Operations. https://training.fema.gov/is/courseoverview.aspx?code=is-368. Published 2016. Accessed October 25, 2016.

6. Fed Regist. 2014;79(20):4840.

7. Fernandez LS, Byard D, Lin CC, et al. Frail elderly as disaster victims: emergency management strategies. Prehosp Disaster Med. 2002; 17(2):67-74.

8. Tomita MR, Mann WC, Fraas LF, et al. Predictors of the use of assistive devices that address physical impairments among communitybased frail elders. J Appl Gerontol. 2004;23(2):141-155. doi: 10.1177/ 0733464804265606

9. US Department of Labor, ADA Facts. https://www.dol.gov/ofccp/regs/ compliance/faqs/ADAfaqs.htm. Accessed August 17, 2016.

10. 28 CFR $\S 35.130$ (d) (the "integration mandate").

11. McDermott S, Martin K, Gardner JD. Disaster response for people with disability. Disabil Health J. 2016;9:183-185.

12. Fed Regist. 1991;56(60):4121.

13. American Speech and Hearing Association. . Augmentive and Alternate Communication (AAC). www.asha.org. Published 2013. Accessed May 13,2016
14. Banerjee M, Tanchak T. Emergency Preparedness Strategies for Persons with Complex Communication Needs. Rockville, MD: The American Speech Language Hearing Association; 2016.

15. Parette P, Scherer M. Assistive technology use and stigma. Educ Train Dev Disabil. 2004;39:217-226.

16. Kailes JI. Emergency Power Planning for People Who Use Electricity and Battery Dependent Assistive Technology and Medical Devices. www.jik.com. Published 2009. Accessed May 13, 2016.

17. Kailes JI, Enders A. Moving beyond "special needs": a function based framework for emergency management and planning. J Disabil Policy Stud. 2007;17(4):230-237.

18. Norwood F. Promising Practices for Evacuating People with Disabilities. Washington, DC: Inclusion Research Institute; 2011.

19. Centers for Disease Control and Prevention. Identifying Vulnerable Older Adults and Legal Options for Increasing Their Protection during All-Hazards Emergencies: A Cross-Sector Guide for States and Communities. Atlanta, GA: US Department of Health and Human Services; 2012.

20. Wu PF, Preece J, Shneiderman B, et al, Community Response Grids for Older Adults: Motivations, Usability, and Sociability. Presented at The American Conference on Information Systems; 2007.

21. Center for Medicare and Medicaid Services. Emergency Preparedness Checklist for Healthcare Facilities. Washington, DC: CMS; 2013.

22. Calahan C, Renne J. Safeguarding independent living: emergency evacuation of the elderly and disabled. InTransition. 2007;7-12:29-31. http://www.intransitionmag.org/spring_2007/v14spring/evacuating_elderly_ disabled.pdf. Accessed October 25, 2016.

23. Christensen KM, Blair ME, Holt JM. The built environment, evacuations, and individuals with disabilities. J Disabil Policy Stud. 2007;17(4):249-254.

24. US Department of Justice, Civil Rights Division, Disability Rights Section. Americans with Disabilities Act: ADA Checklist for Emergency Shelters 2007.

25. US Department of Justice ADA requirements: Service Animals. http: www.ada.gov/service_animals_2010.htm. Accessed May 13, 2016.

26. Communities Actively Living Independently $\mathcal{E}$ Free v. City of Los Angeles, No. CV 09-0287 CBM RZX, 2011 WL 4595993, (C.D. Cal. Feb. 10, 2011).

27. Brooklyn Center for Independence of Disabled v. Bloomberg, $980 \mathrm{~F}$. Supp 2nd 588, 626 (SDNY, 2013).

28. Rutkow L, Taylor H, Gable L. Emergency preparedness and response for disabled individuals: implications of recent litigation. J Law Med Ethics. 2015;43(S1):91-94. http://dx.doi.org/10.1111/jlme.12226.

29. Weibgen AA. The right to be rescued: disability justice in an age of disaster. Yale Law J. 2015;124(7):2202-2679.

30. Cefalu CA, ed. Disaster Preparedness for Seniors: A Comprehensive Guide for Healthcare Professionals. New York, NY: Springer Publishing; 2014. http://dx.doi.org/10.1007/978-1-4939-0665-9.

31. Al-Rousan TM, Rubenstein LM, Wallace RB. Preparedness for natural disasters among older adults: a nationwide survey. Am J Public Health. 2014;104(3):506-511. http://dx.doi.org/10.2105/AJPH.2013.301559.

32. US Department of Education. Emergency Management Research and People with Disabilities: A Resource Guide. https://www2.ed.gov/ rschstat/research/pubs/guide-emergency-management-pwd.pdf. Published 2008. Accessed October 25, 2016.

33. Anderson WL, Wiener JM. The impact of assistive technologies on formal and informal home care. Gerontologist. 2015;55:422-433. doi: 10.1093/geront/gnt165

34. Reeder B, Meyer E, Lazar A, et al. Framing the evidence for health smart homes and home-based consumer health technologies as a public health intervention for independent aging: a systematic review. Int J Med Inform. 2013;82(7):565-579. http://dx.doi.org/10.1016/j.ijmedinf.2013.03.007.

35. Ivey SL, Tseng W, Dahrouge D, et al. Assessment of state and territoriallevel preparedness capacity for serving deaf and hard of hearing populations in disasters. Public Health Rep. 2014;129(2):148-155.

36. US Department of Health and Human Services, Office of the Secretary of Preparedness and Response. HHS Concept of Operations for ESF-8. US DHHS website. http://www.phe.gov/Preparedness/planning/mscc/ handbook/chapter7/Pages/hhsconcept.aspx. Last updated February 14, 2012. Accessed October 25, 2016. 